\title{
Pampa Negro - Agitações, Insubordinações e Conspirações Servis no Rio Grande do Sul, 1803-1850
}

Mário Maestri ${ }^{1}$

Resumo: O artigo aborda as rebeliões, insubordinações e conspirações servis no Rio Grande do Sul, de 1803 a 1850: as agitações servis na Real Feitoria de Linho-Cânhamo; os motes republicanos e abolicionistas pioneiros de Alexandre José de Queirós e Vasconcellos; o Quebra, em 1803, 1822, 1830 e 1831; tentativa insurrecional dos negros minas de Pelotas, em 1848 e a conspiração dos irmãos Botelhos.

1 Insurreições servis; 2. História do Rio Grande do Sul; 3. História da escravidão sulina Abstract: This article discusses slaves rebellion, insubordination and conspiracies in Rio Grande do Sul, from 1803 to 1850: particularly the slaves rebellions at the Real Feitoria de Linho-Cânhado; Alexandre José de Queiroz e Vasconcellos' pioneer republican and abolitionist upheavals; the Quebra, in 1803, 1822, 1830 and 1831; the Pelotas insurrectionary attempt by minas slaves, in 1848, and the Botelhos brothers' conspiracy.

1. Slaves insurrections; . 2 History of Rio Grande do Sul; 3. History of Brazilian southern slavery

\section{1803 e 1822: Rebeldias, Abolição e República}

Em 1776, a reconquista do porto de Rio Grande aos espanhóis pôs fim à asfixia econômica relativa que vivia a sociedade sul-luso-brasileira. Então, a economia mercantil-escravista consolidou-se na capitania de São Pedro. Desde 1780, a produção charqueadora substituía a nordestina no abastecimento dos grandes centros escravistas do Brasil e do exterior, valorizando o gado antes abatido sobretudo pelos couro, sebo, e graxa. (GUTIÉRREZ, 2011). A economia charqueadora acelerou a ocupação da Campanha, das Missões, dos Campos Neutrais e do norte uruguaio por fazendas pastoris de rodeio, apoiadas no trabalho escravizado. (MAESTRI, 2010: 212300; PALERMO, 2013: 115 et seq.). Produzia-se também trigo para o consumo local e exportação, com pequenos plantéis servis. Em 1780, segundo o "Mapa do tenente Córdova", o Sul possuía quase 9.500 euro-descendentes e pouco mais de 5.100 africanos e afro-descendentes $-46 \%$ da população era cativa, excluídos os nativos - 3.388. (LAYTANO, 1958: 35).

A fundação de plantação do linho-cânhamo, no Sul, buscava produzir a matéria-prima para as cordoarias necessárias à marinha portuguesa. A Real Feitoria do Linho-Cânhamo foi instalada em $1^{\circ}$ de outubro de 1783, no Rincão do Canguçu, próximo à vila de Pelotas, com 72 cativos, 44 homens e 28 mulheres, chegados da Real Feitoria de Santa Cruz, no Rio de Janeiro. A eles juntaram-se pouco mais de cem cativos de "confisco", apresados na repressão ao contrabando. A

1 Mário Maestri é professor titular do programa de pós-graduação da Universidade de Passo Fundo. Email: maestri@via-rs.net. 
produção da Feitoria era exportada pela lagoa dos Patos e pelo porto de Rio Grande.

Em setembro de 1788-9, a feitoria começou a ser transferida para o Faxinal do Courita, nas margens do rio dos Sinos, a uns vinte quilômetros de Porto Alegre. Ali, organizou-se criatório pastoril, de uns 3.500 vacuns, cavalares e muares, para produzir carne para a alimentação e animais de montaria e tração. Uns nove mil hectares eram necessários para manter os animais. Duas rezes eram mortas por dia para sustentar cativos e homens livres da feitoria. (BENTO, 1976: 96-106; SANTOS, 1984: 69; MORAES, 1994). O centro produtivo escravista foi desativado em 1824, para a fundação das colônias de São Leopoldo e Novo Hamburgo. (ROCHE, 1969: 94).

Por razões gerenciais e de estruturação, a escravaria da Real Feitoria conheceu crescimento demográfico singular em relação ao dominante no Brasil. Sem a pressão produtiva de empresa mercantil privada, desfrutando relações familiares estáveis, explorando hortas domésticas, os cativos reproduziram-se fortemente. Quando da desativação, a feitoria possuía mais de trezentos cativos. Então, 55 famílias contavam com 174 filhos/netos - 3,1 filhos/netos por unidade familiar, em média. Algumas famílias, como a de Marcos e Leonor Joaquina Pestana, de 41 e 36 anos, tinham oito filhos, de 15 a um ano. (BENTO, 1976: 97-106.) Realidade que contraditava com a expansão demográfica negativa geral da escravidão no Brasil. (CONRAD, 1985: 15 et seq.).

\section{$\underline{1.1 \text { Bailes e fandangos }}$}

Em começos de 1801, a intranquilidade reinava na Feitoria. Então, o padre Antônio Gonçalves Cruz, ex-capelão da exploração, fora nomeado inspetor da mesma, para obter maior produtividade e rentabilidade em exploração onde os cativos plantavam hortas, comerciavam com os vizinhos, trabalhavam em casas privadas e públicas, pouco rendendo aos cofres reais. Em relatório de 1798, inspetor da feitoria reclamara que os cativos dedicavam-se mais a plantação e comercialização de suas roças do que à cultura do cânhamo. Eles plantariam abóbora, algodão, arroz, feijão, mandioca, milho, etc., produção vendida em parte na capital. Pretendendo limitar o tempo dedicado à produção doméstica servil, as novas disposições aumentariam a tensão entre os cativos. (MENZ, 2005: 148; AHRGS, 1978) .

Em 5 de maio de 1803, o padre Gonçalves relatava que havia três noites que não dormia, devido aos "bailes" e "fandangos" que se seguiram ao domingo em que o cativo Manoel José fugira para Porto Alegre, para reivindicar ao governador providências contra administrador certamente acusado de prevaricador e cruel. Os cativos teriam conhecidos e apoios na capital. (AHRGS, RFLC, 
Man. único, padre Antônio Gonçalves Cruz, 5.5.1803.) Três dias mais tarde, o padre-administrador agradecia a prisão do parlamentar e pedia para que fosse mantido em Porto Alegre, até que recebesse "castigo moderado", para exemplo. (Idem; AHRGS, RFLC, Manuscrito único, 1803).

Em 29 de julho de 1803, o padre escrevia ao governador da capitania, o lusitano Paulo José de Sá Gama [1779-1826], comunicando a grave "rebeldia" em que seguiam os cativos. Ela deverse-ia ao "estado a que deixaram chegar estes escravos", que prometera pôr fim ao assumir a administração. Contava o bom padre que, que os cativos negavam-se a aplicar o castigo de "50 açoutes por dia" em [possivelmente] Manoel José, “enviado” de Porto Alegre. “[...] achou-se tal repugnância, nos seus companheiros, para o açoitarem, que foi preciso proceder o castigo em algum para assim o executarem.” (AHRGS, Grupo documental: RFLC, Lata 300.) Durante os açoites, o castigado não deixara de "ameaçar o tal soldado capataz da Estância a quem [ele] tinha desobedecido".

A documentação é lacônica sobre os sucessos. Mais do que rebelião, tratar-se-ia de desobediência ou agressão a capataz, seguida de fuga para reivindicar providências ao governador. Seriam fortes a tensão e solidariedade entre os cativos, certamente nascidos da singularidade das condições de vida conhecidas. Em dezembro de 1814, o padre Gonçalves Cruz teria sido morto, é crível por cativo da feitoria, pois era "dado a infligir maus tratos aos escravos, que eram, muitas vezes, barbaramente castigados", segundo o historiador Leopoldo Petri. (PETRY in CARDOSO: 1977, 74).

\subsection{Alexandre Luís de Queiros, o Quebra}

Em 1803, Alexandre Luís de Queiros e Vasconcelos arrolou cativos pelos caminhos do Rio Grande do Sul para sublevação abolicionista, republicana e separatista, investindo "contra a guarda de São Pedro do Rio Grande”. (SPALDING, 1969: 32). Na época, sua ação inusitada foi apresentada como loucura. Apesar do ato de Alexandre Luís estar sintonizado com os ventos da época, ele segue sendo definida, por parte da historiografia sulina, como ato quixotesco, insano, inconsequente, idealista puro, etc. (BAKOS, 2007: 4; PICCOLO, 1993: 151 ; SPALDING:1969: 32; LESSA, 2000: 129.) Em 1798, fora reprimida a Inconfidência Baiana, movimento republicano de raízes sociais. Naqueles anos, na Europa, entrava em agonia a França republicana e revolucionária. Em 1803, os cativos vergavam os exércitos franceses para fundar o Haiti, a primeira nação americana livre da escravidão. 
Alexandre Luís de Queirós e Vasconcelos nasceu em 19 de abril de 1772, em Cachoeira do Sul, na margem direita do rio Jacuí. Era filho de Maria Eulália Pereira Pinto, de prestigiada família, e do soldado, tenente e sargento-mor de Dragões de Rio Pardo, de mesmo nome, nascido em Vila Boa de Queirós, no Reino, em $1^{\text {o }}$ de janeiro de 1742, e falecido, possivelmente, em Cachoeira, em 1790. Teria tido uma irmã, Maria do Carmo Violante, e um irmão, Fortunado Luís Barreto. Alexandre Luís arrolou-se jovem no regimento do pai, onde teria ascendido a major. Aos 29 anos, em 1801, participou na tropa semioficial de José Luís Jorge Borges do Canto [1875-1805], que após desertar do regimento de Dragões de Rio Pardo e se dedicar ao contrabando, anistiado, com uns quarenta paisanos e guaranis missioneiros, conquistou aos espanhóis as Missões Orientais, quando findava a guerra entre os reinos ibéricos. (SPALDING, 1969: 31-35.)

A proposta revolucionária de Alexandre Luís não vingou, devido sobretudo, por falta de adesão entre os "estancieiros" da província, como propôs, em 1832, o baiano Manoel Antônio Galvão [1791-1850], então presidente da província de São Pedro, em carta a Diogo Antônio Feijó, ministro da Justiça da Regência. Eles estariam mais interessados na "conquista" de Montevidéu e em "grandes aquisições" de "campos e gados", sobretudo ao norte do rio Negro, permitidas pela intervenção luso-brasileira que resultou na Província Cisplatina. (NA, RJ, série IJ (1) 846). Alexandre Luís foi preso e encarcerado no Forte Jesus, Maria, José, na vila de Rio Pardo, na margem esquerda do rio Jacuí. O comandante daquela fronteira, o lusitano Patrício Correia da Câmara, futuro tenente-general, seu aparentado, apresentou-o como louco, certamente para evitar o escândalo de severa punição. Anistiado após “de longos padecimentos" na prisão, Alexandre Luís abandonou a província em direção a Entre Rios, no vice-reinado do Rio da Prata, convulsionado em 1810 pela luta de independência.

Essa e as subsequentes ações de Alexandre Luís, tidas como "ato de loucura, próprio somente do acusado", para salvá-lo da punição e desmerecer sua proposta, foi também desqualificada pela historiografia que, para tal, enfatizou seu cognome, Quebra, compreendido anacronicamente como desordeiro. Alexandre Luís jamais foi realmente resgatado como prócer e pioneiro do movimento republicano e abolicionista radical no Rio Grande do Sul e no Brasil. O fato de sua ação registrar vertente social da luta republicana farroupilha certamente contribuiu para não termos investigação sistemática sobre ele e as raízes gerais de sua ação.

Em 1816-1820, Alexandre Luís integrou as tropas artiguistas que lutavam, desde 1812, pela independência democrática e federalista das províncias do vice-reinado do rio da Prata, contra 
Buenos Aires, a oligarquia de Montevidéu e os luso-brasileiros. Em sua luta, José Artigas [17641850] promoveu a distribuição de terras entre os despossuídos. Em 10 de setembro 1815, o Regulamento Provisório para o Desenvolvimento da Campanha, ditado por Artigas, determinou distribuição de suertes de estancia de uns dois mil hectares aos crioulos pobres; índios, negros livres e cativos fugidos patriotas. Portanto, apenas uma década após o mote de Alexandre Luís de 1803, sua proposta de república de cunho democrático-social era implementada parcialmente nos campos orientais, mostrando não ser pregação anacrônica ou utópica. (ELOY, TOURON, TORRE, RODRIGUES, 1970: 17 et seq.).

\subsection{Independência e Abolição}

Quando José Artigas foi derrotado, em 1820, e procurou refúgio com alguns índios e excativos patriotas no Paraguai do doutor José Gaspar de Francia, Alexandre Luís, promovido a sargento-mor e já conhecido como Quebra - "valente", "forte", "respeitável" -, retornou ao Rio Grande, estabelecendo-se em Cachoeira do Sul, onde sua família possuía raízes e terras, para desempenhar agitação republicana e abolicionista. (SPALDING,1969: 1, 32; AN, RJ, série IJ (1) 846.)

O caráter monárquico, unitário e centralizado que assumiu a independência no Brasil em 1822 deveu-se sobretudo à vontade dos grandes proprietários provinciais de romperem com Portugal, sem comprometer a escravidão. (MAESTRI in ANDRADE, 2001, 49-80.) Em algumas províncias, o movimento pela independência agitou a escravaria. Ela acreditara que, com o fim do regime colonial, chegara também o da servidão. No Sul, a crise da independência também motivou sobressaltos.

Aproveitando a deixa, possivelmente em 1822, Alexandre Luís, com já cinquenta anos, libertou os homens livres e cativos presos na cadeia de Cachoeira do Sul e ordenou a degola dos portugueses, no que não foi obedecido. Pretenderia associar o fim da escravidão à independência de Portugal! O Quebra teria entregado o bastão e a veste do comandante da vila, o lusitanto José Carvalho Bernardes, ao liberto Pedro, seu companheiro de armas na luta artiguista. Para escândalo geral, o liberto desfilou garbosamente vestido pelas ruas de Cachoeira proclamando que, na nova ordem, reinaria a "igualdade dos povos". (Idem) Cercado e preso, foi enviado à Corte, onde, novamente sob perigo de prisão, foi indultado por dom Pedro, talvez lembrado por seus poderosos parentes de sua "loucura" e para não descontentar os criadores sulino, quando ainda não esquentara 
o trono. Libertado, teria retornado a Cachoeira do Sul. Mais duas vezes, anos mais tarde, voltaria a levantar a bandeira da revolução política e social na província. (SPALDING, 1969:1, 33)

\section{$\underline{1.4 \text { Novamente a Feitoria }}$}

Também a Feitoria de Linho Cânhamo agitou-se em 1822. Em 2 de agosto, José Tomás de Lima, inspetor da exploração, comunicava graves acontecimentos às autoridades provinciais. Sabendo que cativos abandonavam as senzalas, à noite, para roubarem mantimentos em roças da Feitoria, a umas duas léguas da sede - "Guari" -, mandara "soldados do destacamento" prender os que cria serem os "roubadores". Indignados com a ação, os cativos entraram "nas suas senzalas" de onde saíram "armados", atacando e obrigando os "soldados" a se "retirarem ao quartel". Os trabalhadores escravizados viveriam em moradias unifamiliares. Para prender os "levantados", o administrador reunira "todo o destacamento". "Engrossando" o "partido" dos cativos, "instigado pelas mulheres, que gritavam" que matassem os soldados e oficiais, o administrador retirou-se, devido à "desproporção" das forças e por "que se ia tornando mais sério o caso". Após o confronto, "a maior parte dos pretos levantados", sobretudo os "mais criminosos", desapareceram. Os restantes permaneceram na Feitoria. Segundo o documento, o moral da tropa era baixo e os soldados estariam “aterrorizados". Razão pela qual o Inspetor pediu um "reforço de oito soldados de linha". (AHRS, RFLC, man. único, José T. de Lima, 28. 1822.)

Dez dias mais tarde, José Tomás escreveu novamente comunicando que os "pretos da Feitoria Nacional", submetidos à pena de quatrocentos açoites, por ordens superiores, devido ao "alevantamento", encontravam-se "muito feridos", em péssimas condições. Haviam levado duzentos açoites e não estariam em "circunstâncias de continuar o castigo". Pedia a suspensão do suplício. Os pretos Ventura e José da Glória, “cabeças” do movimento, foram enviados para Porto Alegre. Na Sul, na época, a Justiça condenava cativos homens a mil e mil e quinhentas chicotadas, surrando-os até a morte. (SOLIMAR, 2006: 145 et seq.). No rol dos cativos da feitoria de 1824, não há registro de nenhum Ventura. Talvez tivesse tido outra destinação, devido à rebeldia. Ao contrário, José da Glória, viúvo, na época dos fatos com 79 anos, tinha três filhos, de 20, 17, 14 e 12 anos. (BENTO, 1976: 97-106.)

\subsection{Produção Singular}

A Feitoria não pode ser identificada às unidades escravistas coloniais. Nessa propriedade estatal, os cativos contavam com privilégios incomuns, herdados possivelmente da Real Feitoria de 
Santa Cruz, do Rio de Janeiro, até 1759 de propriedade dos jesuítas: núcleos familiares estáveis; relativa liberdade de movimento; direito a hortas, etc. A constituição de casais entre os cativos da Feitoria obedecia o padrão das fazendas das ordens religiosas, fortalecendo os cativos relativamente diante dos administradores. (MAESTRI, 1988). É certamente abusiva a proposta de que, devido àquelas condições singulares, os cativos "fossem [...] impondo a sua própria administração". (JOHANN, 2011: 18.)

A Feitoria jamais alcançou sucesso econômico, sob a direção de administradores preocupados sobretudo com seus interesses. Em suas Memórias ecônomo-politicas, escritas poucos anos antes da Independência, o charqueador Antônio José Gonçalves Chaves [1781-1837], ironizava que o padre Gonçalves fizera no estabelecimento "adiantamento", "não em plantação do cânhamo", mas fundando "grande fazenda de criação de gado". Sobre o sucessor do padre, o tenente José Manuel Antunes da Frota, disse que chegara com "o privilégio de roubar tudo quanto houvesse na Feitoria, uma vez que repartisse [...]”. (CHAVES, 2004: 141-2.)

Chama a atenção que os cativos saíssem, sem problemas, à noite, para buscar alimentos nas roças da propriedade. Quando da agitação, o inspetor apressara-se a explicar que os pretos eram "mais do que nunca bem fornecidos de sustento" e que "vendiam" "prontamente" os "roubos" que faziam. Talvez nesse então tivessem sido suspendidas as roças domésticas e, insuficientemente alimentados, os trabalhadores escravizados abasteciam-se furtivamente nas roças. A tentativa de reprimir o costume levara à rebelião. A documentação sugere a vontade do inspetor de acalmar os ânimos e não agravar os fatos, que possivelmente o comprometeriam. Quando viu que o caso tornava-se "mais sério", retirou-se. Mais tarde, pediu a comutação do castigo. Na correspondência, refere-se ao crime de "levantamento" e não de "insurreição". Os cativos escapados teriam, pouco a pouco, retornado, ou se deixado aprisionar. Conheciam na Feitoria condições de existências desconhecidas pelos demais cativos e melhores, talvez, à vida incerta em um quilombo.

\subsection{Novamente o Quebra}

No fim da guerra da Banda Oriental por sua independência, "em vésperas da Batalha do [passo do] Rosário", em 20 de fevereiro de 1827, nas proximidades da vila de Rosário do Sul, Alexandre Luís teria integrado as tropas rio-grandenses que, sob as ordens de Bento Gonçalves, Bento Manuel, Sousa Netto, etc. desertaram ativamente, facilitado a derrota do Império e a independência oriental. (AN, RJ, ser.IJ(1)846). Já sob as ordens do general portenho Carlos Maria 
Alvear, o coronel Alexandre Luís recebeu o comando de regimento republicano de Libertadores do Rio Grande, para a libertação e separação da província e, certamente, sua federação com as Províncias Unidas. A iniciativa não prosperou devido à paz entre o Rio de Janeiro e Buenos Aires e o reconhecimento da independência da Banda Oriental. (SPALDIN, 1969: 1, 33.) Segundo Walter Spalding, Alexandre Luís teria vivido discretamente na província. Em 1831, no contexto da mobilização liberal contra dom Pedro e os corcundas, o Quebra apresentou-se na capela de Caçapava do Sul, para novamente arregimentar e libertar cativos pelas estâncias vizinhas para que lutassem pela república, abolição e possivelmente secessão da província. Caçapava do Sul se encontra na Campanha, a uns $150 \mathrm{~km}$. da fronteira com o Uruguai. Era a terceira vez que proclamava a abolição da escravatura e a república no Rio Grande do Sul.

Propõe-se que o levante de Alexandre Luís, em Caçapava, estivesse articulado com a conspiração reprimida, em São Leopoldo, em 29-30 de novembro, na mesma época. O movimento seria chefiado por João Manoel de Lima e Silva, comandante do $28^{\circ}$ Batalhão de Caçadores, e nele participariam o major Carlos Frederico Otto Heise; os capitães Samuel Gottfried Kerst e Gaspar Eduardo Stepanousky, além de soldados alemães daquele batalhão e colonos alemães. (TRAMONTINI, 2000: 147-153). O major Carlos Frederico Otto Heise lutara "pela independência da Bolívia e do México antes de vir para o Brasil”, para participar da Guerra Cisplatina. Ele seria destacado combatente farroupilha. (FLORES, 1995:23).

João Manoel de Lima e Silva [1805-1837], tio mais jovem do futuro duque de Caxias, casou-se com a Maria Joaquina, irmã do coronel José de Almeida Corte Real, dirigente farroupilha. Em 1834, foi novamente inocentado da acusação de conspirar com o blanco Juan Antonio Lavalleja para a sesseção do Rio Grande e federação ao Uruguai. O militar participou do levante de 1835, comandando as tropas farroupilhas. (WIEDERSPAHN, 1994: 22 et seq) Primeiro general farroupilha, João Manuel impulsionou precocemente o alistamento de libertos e cativos, formando o $1^{\circ}$ Corpo de Cavalaria de Lanceiros Negros com mais de quatrocentos integrantes. Aprisionado por partida imperialista, foi assassinado em 16 de agosto de 1837, nas Missões. Tal era o ódio monarquista contra ele que sua sepultura em Caçapava do Sul seria violado e seus ossos dispersos.

\subsection{Por Uma Última Vez}

Em abril de 1831, os liberais depuseram dom Pedro. Em 25 de dezembro de 1831, quando se festejava o Natal, Alexandre Luís chegava outra vez a Caçapava do Sul talvez de 
Montevidéu, não para pregar a fraternidade entre escravistas e escravizados, monarquistas e plebeus. No dia 29, o juiz de Paz e Comandante do Regimento 22 de Cavalaria da $2^{\text {a }}$ Linha denunciou ao presidente da província, Manuel Galvão, que o Quebra pregava "revolução" com os "negros", através da "exterminação dos brancos", na qual assumiria como "primeira autoridade provincial. Obraria para "sublevar os povos", para "incorporar" a província "ao Estado Oriental do Uruguai, promovendo primeiro a insurreição dos escravos”. (AN, RJ, ser.IJ(1)846).

Segundo correspondência, de $1^{\circ}$ de fevereiro de 1832, do presidente da Província ao padre Diogo Antônio Feijó, Ministro da Justiça, Alexandre Luís teria "aliciado" uns quarenta cativos do “sargento-mor Damazo dos Santos de Menezes", em chácara próxima à povoação. Em correspondência anterior, de dezembro, a Manuel Galvão, o Juiz de Paz de Caçapava do Sul afirmara que aquele escravista teria, por todo, "trinta escravos". (AHRGS, Justiça, Caçapava do Sul, Maço 5, corr. do Juízo de Paz.) Devido à agitação, o juiz de Paz pedira ajuda ao presidente da província, já que o revoltoso se acharia “surtindo de [muita] pólvora”. Para prendê-lo, partiram para a localidade o sargento-mor Lourenço José Ferreira e o tenente Claro, no comando de praças de pré.

Entretanto, uma reunião de cidadãos na porta do Juiz de Paz, exigindo a prisão de celerado, levou Alexandre Luís a fugir a cavalo, com seu "escravo", que denominava de "capitão da Pátria", armados de trabucos e pistolas. Os fugitivos foram perseguidos por cavaleiros, sob às ordens do tenente Claro. Em um potreiro, cercado de muro de pedra, os perseguidos apearam-se e ganharam "um mato grande". (AN,RJ,ser.IJ(1)846). Em 30 de dezembro, os fugitivos obtiveram montarias em estância da região, onde Alexandre Luís renovara "suas ameaças de revolução com o favor dos negros", antes de seguir, talvez para sua "estância Palma", no "distrito de Cachoeira" do Sul, a nordeste de Caçapava do Sul. Um "destacamento de doze praças", reforçado por paisanos armados, municiados e pagos pelo juiz de Paz e moradores, foi enviado para perseguir ao Quebra "por toda a parte até prendê-lo ou botá-lo para fora da Província". (AN,RJ,ser.IJ(1)846).

Segundo o presidente da província, falhara a "partida encarregada de fazer a prisão", por "falta de coragem", segundo ele compreensível, "quando [de] uma grande revolução" ou do aparecimento inesperado de "facínora". Mais uma vez, o destemido Quebra e Pedro, seu companheiro de lutas e ideais, abriram caminho pelas armas. O presidente da Província não concordaria com as propostas de simples prisão ou expulsão. Em 19 de janeiro, determinava ao juiz de Paz de Caçapava que, "no caso de resistência", o facinoroso deveria "ser morto na conformidade do artigo 118 do Código Criminal”. Alexandre Luís, então com 59 anos, era acusado do pecado 
mortal de "despertar os desejos da liberdade aos cativos, avivando-lhes lembranças que talvez não mantivessem até o presente". (AN,RJ,ser.IJ(1)846).

Walter Spalding escreveu nota biográfica de Alexandre Luís de Queirós e Vasconcellos, na qual não se refere aos fatos de 1831, não detalha com precisão suas fontes e parece superar discursivamente os hiatos de informação. Segundo ele, Alexandre Luís faleceu na fronteira, em 1833, tendo ao lado Pedro e alguns cativos. O que é improvável, devido o registro de sua prisão, seis meses após os sucessos. Em 2 de junho de 1832, o presidente da província oficiava a Diogo Feijó: "Tendo oficiado a Vossa Excelência em data do $1^{\circ}$ de fevereiro [...] dando parte de que ocorrera a vila de Cachoeira [sic], e das providências subsequentes para a prisão de Alexandre Luiz de Queiroz [...], participo agora [...] que se acha preso este desgraçado velho, e que imediatamente que se recolha o ouvidor da Câmara será processado na Junta de Justiça. Previno a Vossa Excelência que o sobredido Alexandre Luiz já esteve alienado do juízo mais de uma vez segundo me informaram”. (AN,RJ,ser.IJ(1)846).

\subsection{Insurreição Escravas Durante a Guerra Farroupilha}

O confronto entre os proprietárias foram sempre momentos singulares para fugas e revoltas de cativos. De 1835 a 1835, o Sul foi dilacerado por guerra civil que fragilizou a submissão servil, facilitando movimentos de fugas e aquilombamentos. Em Pequena história de Porto Alegre, Walter Spalding refere-se a uma "insurreição de escravos", quando Porto Alegre já retornara ao controle do Império. Portanto, após 15 de julho de 1836. "Outro fato que muito agitou a Câmara foi uma insurreição de escravos, insurreição esta provocada pelos farroupilhas que haviam criado corpos militares exclusivamente de pretos a quem davam a liberdade em troca do serviço militar. Alguns foram presos e castigados, mas a maioria conseguiu fugir e unir-se às forças republicanas [...]." (SPALDING, 1967: 97.)

Em 12 de outubro de 1838, Manoel José de Freitas Travasso Filho, chefe de Polícia interino, comunicava à câmara de Porto Alegre que deliberaria no dia seguinte sobre a correspondência referente à tentativa de "insurreição de escravos" apenas descoberta na cidade e sobre a necessidade de que a câmara procedesse no cumprimento estrito do determinado pelas Posturas quanto ao "ajuntamentos de escravos e pretos forros nas tabernas, algazarras e cantarolas pelas ruas da Cidade [...]". Propunha também que a câmara procedesse "contra os Fiscais" "omissos no exato cumprimento dos seus deveres". (AMPA, 13 de outubro de 1838: 252 e verso). 
O Aviso de 3 de agosto de 1841, do Ministério da Justiça do Império, ao presidente da Província, pede investigação de informação recebida pela Repartição dos Negócios Estrangeiros sobre conspiração para sublevar cativos africanos da Província. (AHRGS, Avisos. Do Ministério de Justiça ao Presidente da Província. Cód. B.1.108). Nos dez anos de guerra civil farroupilha, os cativos foram arrolados em grande número nas forças armadas, vista a pouca disposição dos homens livres de morrerem pela República. No fim do conflito, boa parte das tropas rebeldes era formada de africanos, afro-descendentes, nativos e gaúchos. (FLORES, 2004: 9 et seq.) Os cativos serviram-se do confronto para escafederem-se sobretudo para o Uruguai. Após a Guerra, anotou-se pouco menos de mil cativos possivelmente homiziados no Uruguai. Muitos quilombos surgiram naqueles anos no Sul. (PETIZ, 2006: 95 et seq.; MAESTRI in REIS \& GOMES, 1996: 291-331.)

\section{Os anos 1840: A Insurreição Mina de Pelotas}

Em 1845, quando do fim da guerra, boa parte da população cativa, com destaque para o meridião da província, morrera, aquilombara-se, fugira para além-fronteira. As necessidades de charque, couros e mulas da cafeicultura em expansão ensejaram rápida retomada da produção regional e reposição das escravarias, aumentando a proporção de cativos novos entre ela. Dados de 1846 registram que a proporção de escravizados em relação aos livres caíra de taxas superiores aos $30 \%$ para pouco menos de $21 \%$. Porém, em 1858 , a população cativa dobrara e constituía $25,19 \%$ da população regional, em forte expansão absoluta, devido à retomada da imigração colonial. (MAESTRI, 2002: 89.)

Os proprietários temiam a concentração de mais de três mil cativos nas charqueadas, nas olarias e de Pelotas, o maior polo escravista sulino. Em 1833, Pelotas possuía 10.873 habitantes, sendo que 5.623 eram cativos; 3.911, livres; 1.137, libertos; e 180 índios. (AHRGS. Autoridades municipais. Câmara mun. Pelotas. 1833.) Ainda em 1884-5, quando do movimento de emancipação, sob a cláusula da prestação de serviços gratuitos, a população servil mantinha-se quase a mesma: "Dos cinco mil escravos que a cidade tivera, dois mil eram servidores domésticos ou trabalhadores do porto e mil eram usados na agricultura. Os outros dois mil, segundo o presidente [da Província], trabalhavam nas charqueadas [...]." (CONRAD, 1978: 253.). Apenas numericamente as forças militares locais eram inferiores aos cativos. Entretanto, os escravizados jamais agiram unidos e sobretudo a Guarda Nacional podia ser mobilizada rapidamente. (RIBEIRO, 2005: 139 et seq.)

Em 1848, a tentativa insurrecional dos cativos minas pelotenses confirmou os 
temores dos escravizadores. J. C. Miranda de Castro, presidente da Província, refere-se ao movimento em seu relatório à assembleia provincial. "O juiz de Direito da câmara do Rio Grande e o delegado de Polícia da cidade de Pelotas participaram recentemente ter havido denúncias, desde o princípio de janeiro deste ano, de um plano entre os negros da nação mina, existentes nesta última cidade e nas charqueadas e olarias [...], para uma insurreição. "Tomadas as provenientes precauções, e continuando as denúncias de que, o dia 6 de fevereiro último era aprazado para o rompimento; forçoso foi ao delegado mandar prender os indigitados de estarem no plano. Até o dia 6 do mesmo mês constava, oficialmente, que mais de 30 dos referidos negros estavam presos. Não consta ainda ter-se descoberto ramificações." (RELATÓRIO, 1848.)

\subsection{Repressão ao Movimento}

Ofício de José Vieira Viana, delegado de Polícia de Pelotas, de 11 de fevereiro, ao brigadeiro José Fernandes dos Santos Pereira, comandante da cidade e da fronteira do Rio Grande, circunscreve o ocorrido: "Por denúncias que tive, de que havia um plano para a insurreição dos negros minas desta cidade e suas imediações, que devia aparecer no domingo passado, 6 do corrente mês [fevereiro], dei, na véspera deste dia, todas as providencias ao meu alcance para atalhar este mal; e até ontem, das indagações que fiz a respeito, e pelas confissões dos negros presos e castigados, não passava o plano dos referidos negros minas".

Para o chefe de Polícia, haveria o dedo oriental no movimento: “[...] mas de ontem para cá tem aparecido suspeitas de haver aliciadores do Estado vizinho [Uruguai]; e um tropeiro, proximamente chegado do mesmo Estado, notícia que passando em Arroio Malo, haverá doze dias, ali lhe certificaram que os escravos deste município se haviam levantado, saqueado a cidade, e passado para os blancos, no sobredito Estado [...]." (O Rio Grandense, Rio Grande, 19.2.1848. MAESTRI, 1984: 144-148). No Uruguai, Manuel Oribe, aliado de Juan Manuel de Rosas, desafeto do Império, mantinha Montevidéu sitiada, exercendo pressão sobre os estancieiros escravistas riograndenses no norte do país.

Quatro dias mais tarde, o delegado de Polícia de Pelotas oficiava ao brigadeiro João Frederico Caldwel, comandante das Armas da Província, declarando que em janeiro tivera "denúncias" de "plano de insurreição de escravos" confirmadas por idêntica notícia "dias depois", tomando por isso "medidas de prevenção e de cautela". Porém, apenas em 5 de fevereiro, confirmada a conspiração por Luiz Manoel Pinto Ribeiro, "por lhe a haver comunicado um seu 
escravo de nação mina", acompanhado do capitão comandante da Polícia, fora à chácara daquele proprietário para inquirir o cativo, que falou do plano para o qual "tinha por vezes sido convidado". O alcagueta disser haver "armas" e que o movimento eclodiria no dia seguinte, domingo, 6 de fevereiro. José Vieira Viana levou "com cautela, o referido negro" para a sua "casa" e determinou que o capitão da Polícia procedesse a prisão dos apontados "como aliciadores do projetado plano", que possuiria "uma divisa" e "designação de postos" na conspiração. Com alguns soldados, o capitão prendeu "negros indicados pelos já presos e pelas denúncias anteriores". Enquanto escrevia, seguiam as prisões, já superiores a meia centena.

O delegado comunicava que, após açoites, ministrado em "acordo da maior parte de seus senhores", os conspiradores começavam a ser entregues aos proprietários. Apenas um forro fora preso "por saber do plano e o não ter comunicado como confessou". Não havia fugas e indícios de envolvimento de "pessoa alguma branca, nacional ou estrangeira", apesar dos "boatos e suspeitas" da "mão oculta do Estado vizinho". A conspiração restringir-se-ia aos "negros minas" da "cidade, charqueadas e olarias" de Pelotas. (PICCOLO, 1992: 28) A descoberta da conspiração exacerbou a imaginação dos escravistas. Em 9 de fevereiro, quatro dias após a repressão do movimento, o delegado Viana levava ao tenente-coronel Serafim Inácio dos Anjos, chefe interino de Legião da Guarda Nacional em Pelotas, a "notícia que grande número de escravos do segundo distrito deste termo" reuniram-se e seguiram "para a serra dos Taipes, em número pouco mais ou menos de duzentos". Pedia a "força necessária" para "acautelar, prevenir e prender" os "fugidos, sedutores e implicados no fato", "naquele distrito" ou no do serro da Buena", de onde chegava "igual notícia", “não oficial”. (O Rio-Grandense, Rio Grande, 19/02/1848.)

No dia seguinte, o tenente-coronel Serafim Inácio dos Anjos respondia ao delegado dizendo que, ao receber o ofício, determinara reunião dos guardas nacionais "da costa da Serra, nos pontos de Monte Bonito e Passo do Retiro", onde amanheceram no "dia 9 para 10, mais de 100 homens". O próprio tenente-coronel seguira no dia 9, "pela costa do arroio Pelotas acima", local das charqueadas, para informar-se sobre e providenciar patrulha armada de moradores da região. Ao nada constatar no serro da Buena, desmobilizara os guardas nacionais. Remetia cativo, capturado no Monte Bonito, que dizia andar fugido ao seu escravizador, João Bittancourt, havia dois meses. Em 12 de fevereiro, o tenente-coronel relatava suas providências a Tomás José de Campos, comandante superior interino da comarca do Rio Grande: “Os sustos de que se achava este povo possuído, com a notícia do levantamento de escravos minas, e outras notícias aterradoras, os julgo todos 
terminados." (O Rio-Grandense, Rio Grande, 19/02/1848.)

\subsection{Somente os Negros Minas}

Em carta de 15 de fevereiro, Tomás José de Campos, escrevia ao seu superior, José Fernandes dos Santos Pereira, brigadeiro comandante da cidade de Pelotas e da $1^{\circ}$. brigada do Exército da fronteira do Chuí, questionando o ofício do delegado de Polícia, publicado no periódico Nova Época, $\mathrm{n}^{\circ}$. 152. Naquela correspondência, o delegado pedia ao brigadeiro providências, pois temia que a tentativa de insurreição dos minas fosse "promovida por indivíduos do Estado vizinho". Tomás José afirmava que a "tentativa dos escravos" abrangeria apenas os "da nação mina", não havendo "aliciadores do Estado vizinho" ou "elementos de desordem. [...]." Ele registra igualmente a tradicional disposição das autoridades de desmobilizar os temores e a agitação: "Penso que medidas policiais e de cautela são as que muito convém; e creio nocivas as aterradoras notícias que unicamente se fundam em vagas suspeitas; pois que não me consta, haja a polícia, até agora, descoberto armamento algum [...]. Julgo achar-se já suplantado o levantamento dos escravos minas [...]; repetindo a vossa excelência que todo o barulho ocorrido de preto só compreendia os desta nação [...]." (O Rio-Grandense, Rio Grande, 19 de abril de 1848.)

Em posse das informações que recebera, a presidência da Província tomara providência e expressou sua visão dos fatos. Em "Expediente", de 17 de fevereiro, ao comandante provincial das Armas, ponderava a "necessidade de reforçar a ala do $8^{\circ}$ Batalhão de Caçadores que se acha na cidade de Pelotas", enquanto não fosse enviado um "batalhão completo" e melhor armado da Guarda Nacional do município. Enviava ao juiz de Direito da comarca do Rio Grande a canhoneira Caçapava e dizia que não viesse "tomar assento na Assembleia Legislativa Provincial". Em "Expediente" do dia seguinte, 18, informava que a "diretoria do Arsenal de Guerra" mandara "encaixotar 200 armas de infantaria" destinadas ao "coronel comandante superior da Guarda Nacional da comarca de Rio Grande”. Repreendia o delegado de Polícia de Pelotas, "que, sendo sabido das autoridades policiais, já em princípios de janeiro, a conspiração dos negros, de tão sério acontecimento não tivesse dado parte" tomando a "responsabilidade sobre si". Lastimava que, após conhecido, abortado e reprimido, a conspiração, ele dissesse que era "pouca a força simultânea da $1^{\text {a }}$ Linha e de policia." (Rio-Grandense, Rio Grande, 20 de abril de 1848.)

\subsection{Movimento Complexo}

Resumindo os fatos. Em inícios de janeiro, o delegado de polícia de Pelotas recebera duas 
denúncias sobre eventual conspiração entre cativos do município. Em 5 de fevereiro, sábado, a delação de cativo mina ao seu escravizador confirmara o movimento e sua eclosão no dia seguinte. Então, o delegado providenciara a prisão dos denunciados na cidade, olarias e charqueadas, em pleno funcionamento. Não temos detalhes da organização do complô, que se restringiria a meia centena de cativos "minas" que teriam se dado "uma divisa" e designados "alguns" "postos" de comando. Não teriam sido encontradas armas, o que sugere que seriam utilizados os instrumentos de trabalho - facões, machados, ferros, etc. Já que a volta à África era quase impossível, talvez pretendessem fugir para o Uruguai, dominado quase completamente pelos blancos. Estas últimos combatiam o Partido Colorado que era apoiado pelos estancieiros negreiros sulinos do norte do país. Os blancos mobilizavam-se pela autonomia do Uruguai e respeito da abolição da escravatura, em 1842.

Em 17 de fevereiro, o delegado de Polícia de Pelotas oficiava ao comandante provincial das Armas enfatizando a possível influência blanca na conspiração. Dois tropeiros brasileiros, chegados do Uruguai, contaram que, "havia mais de 20 dias", os castelhanos falavam "que a escravidão desta província estava toda livre". Segundo eles, os cativos eram ali esperados. Mais ainda, "em menos de um mês", cem ou mais cativos haviam fugido para o "departamento de Thianna [?]" para assentarem "praça" nas tropas brancas. (PICCOLO, 1992: 29-30). Eram chamados de "minas" os africanos escravizados no entreposto da fortaleza de São Jorge da Mina, erguida, em 1482, pelos portugueses, na Costa do Ouro, na atual Gana. Dados parciais sobre os africanos alforriados em Pelotas [1832-1849] assinalam que mina era a nacionalidade mais numerosa no município, seguida pela soma de todos cativos do "complexo angolano" - "angolas", "benguelas", “cabindas", etc. (SIMÃO, 2002: 87).

Nos inventários de charqueadores pelotenses, de 1850-1888, o historiador Euzébio Assumpção identificou 189 africanos com nacionalidade declarada: dentre eles, 98 cativos eram minas e os 91 restantes possuíam vinte outras nacionalidades! Mais de 50\%! (ASSUMPÇÃO, 2013: 142 et seq.). A repressão da insurreição dera-se devido à denúncia de cativo, que foi recompensado por sua traição. A carta de alforria do mina Procópio reza: "Digo eu abaixo assinado, que sendo senhor e possuidor do um negro de nação mina, de nome Procópio, ao mesmo dou liberdade de hoje para sempre, por tratar de sua vida como liberto que fica sendo, em razão de ter recebido do Ilustríssimo Senhor José Vieira Viana, Delegado de Polícia desta cidade a quantia de setecentos noventa e sete mil réis, que mandou agenciar pela a alforria do dito escravo, por haver o mesmo denunciado uma 
insurreição que estava projetada entre os mais negros de sua nação, os quais denunciou e entregou àquelas autoridade que os mandou prender e corrigir, e por verdade do empreendido, e para que dito o escravo possa gozar de sua inteira liberdade, lhe passeia presente carta, que fiz e assinei. Pelotas, três de março de mil oitocentos quarenta e oito.” (APERGS, Registro Ordinário, Pelotas, 4.05.184727.11.1849. p. 30).

\section{1850 e a Abolição do Tráfico: Ladinização e Criolização}

Em 1850, o fim do tráfico internacional de africanos escravizados determinou três fenômenos fundamentais: 1) a queda absoluta e relativa da população escravizada, devido, por um lado, às alforrias, mortes, fugas e sobretudo à baixa expansão demográfica e, por outro, o crescimento da população livre; 2) a ladinização e criolização dos feitorizados e sua crescente homogeneidade cultural e linguística relativa; 3) a concentração da mão de obra cativa na cafeicultura do Centro Sul, através do tráfico inter-provincial, desescravizando fortemente importantes regiões do país. (COSTA, 1982: 41 et seq.).

Desde 1850, o Rio Grande teria passado a exportar - e não a importar - cativos para o Centro-Sul, com destaque para os anos 1874-1884, quando se transformou no principal exportador de cativos para a cafeicultura, segundo "Relatório do Ministério da Agricultura", de 1884 - com 14.302 trabalhadores cativos vendidos. Entretanto, segundo os dados disponíveis, até 1881, a população escravizada seguiu crescendo em números absolutos, certamente em boa parte devido à expansão dos cativos das fazendas pastoris. (WEIMER, 1991: 33; CONRAD, 1975: 346, 351; BENTO: 1976, 119). Nos anos 1872-1890, a população sul-riograndense dobrou de 446.962 para 897.455 habitantes. (FEE, 1981).

Nos anos 1850, temos registros de agitação nas senzalas, reprimidas antes de eclodirem; de denúncias talvez fruto do temor dos escravistas, exacerbado pelos conflitos no Uruguai; de movimentos de diversos sentidos, envolvendo cativos. Em 13 de março de 1852, poucas semanas após a vitória do Império e de Justo José de Urquiza sobre Juan Manuel de Rosas, em monte Caseros, o presidente da província escrevia ao ministro da Justiça, enviando-lhe os "mapas e relatórios" sobre a segurança no Rio Grande. Assinalava que, "apesar do estado excepcional” desta Província, não aumentara o "número de crimes", destacando-se apenas as "duas agressões dos indígenas" e a "recente tentativa de insurreição de escravos na Freguesia de Belém, a duas léguas desta capital $[\ldots] "$. 
Mesmo não dando muito "crédito" à "denuncia" de "escravo do vigário da referida freguesia", fora ao local com o chefe de Polícia para proceder "eficazes diligências", indagando por "um dia inteiro", "pessoalmente, dos moradores e de alguns escravos, que por suspeito têm sido presos". Não teria descoberto "fundamento sério de semelhante tentativa". Registrava que cativos presos confessaram convite "para insurgir-se contra seus senhores por outro, que fugiu no ato de ser preso". Estranhava a existência de insurreição séria, "tão próxima desta capital”, onde existia "guarnição de trezentas e tantas praças de Guardas Nacionais e de Polícia", e escassa população escravizada [sic]. Tudo seria iniciativa do cativo que escapara, que teria tido o "pensamento de vingar-se de seus senhores", convidando para tal companheiros, sendo denunciado por um que revelou o "projeto". (AN,RJ,ser.IJ(1)578).

\subsection{Um Preto Oriental Conspirador}

Em 1854, no relatório à Assembleia Provincial, João Lins Vieira Sinimbu referiu-se a "boato vago que em dias de fevereiro" correra a vila de Rio Grande, sobre levante servil. Investigações policiais não acharam o "mais leve indício de fundamento" sobre o fato. (RELATÓRIO, 1854:4 ) Anos mais tarde, em 23 de abril de 1858, o secretário da Polícia oficiava ao presidente da Província pedindo que remetesse para o Rio de Janeiro, no dia seguinte, no vapor Caxias, o "oriental preto Francisco Antonio Dias", enviado da vila de Santana do Livramento, na fronteira com o Uruguai, como "suspeito de ter sido o cabeça da insurreição de escravos que teria tido lugar naquela vila", já que seria "homem perigoso" para a província. No mesmo dia, o presidente da província remetia ao ministro e secretário dos Negócios da Justiça, na Corte, a proposta do chefe da Polícia de "deportação" para o Uruguai do "preto oriental Francisco Antônio Dias, suspeito de haver sido a cabeça da insurreição de escravos" que "houve" lugar "na vila de Santana do Livramento".

Afirmava na correspondência: “"[...] nessa ocasião faço seguir para essa Corte, a entregar ao dr. Chefe de Polícia, o referido oriental, [...], por não convir que ele continue a permanecer na província." Em 26 de agosto, o ministro respondia negativamente à sugestão de envio ao Uruguai, lembrando que ele poderia voltar à proximidade da fronteira, para "prosseguir nos atos criminosos" que cometera. Possivelmente em 19 de outubro, seguia para a Corte, pelo vapor Imperador, segundo determinara o ministro da Justiça, o afro-uruguaio Francisco Antônio Dias, acompanhado por um "praça", acusado de "ser cabeça de insurreição de escravos que devia ter lugar na vila de Santana do Livramento", em janeiro daquele ano. A prisão e envio à Corte fora determinado ao Chefe de 
Polícia da província através de Aviso da Repartição de Justiça em 16 de outubro. A documentação afirma que o movimento ocorrera e que fora descoberta antes de sua eclosão, o que é mais provável. (NA, RJ, ser.IJ(1)851; AHRGS, corr. passiva de outras províncias, maço 3.)

\subsection{9: A Revolta dos Irmãos Botelhos}

Lemos no relatório de Joaquim Fernandes Leão à Assembleia Provincial, de novembro 1859: “Cabe aqui consignar dois fatos de insurreição de escravos, que infelizmente teriam lugar em alguns pontos da Província, se enérgicas providências, tomadas a tempo, não os fizessem abortar [...]. A primeira tentativa era promovida em Capivari, Encruzilhada e Herval, pelos desertores do Exército de [nome] Botelhos, e vários outros criminosos. O movimento de forças para esses pontos, a atividade das autoridades policiais respectivas e do comandante superior do Rio Pardo, fez recuar esses criminosos do propósito em que estavam. [...]." (RELATÓRIO, 1859:3) Capivari e Encruzilhada do Sul localizam-se, respectivamente, a uns vinte e quarenta quilômetros, a sudeste e ao sul de Rio Pardo.

Em 31 de março de 1859, José Joaquim de Andrade Neves, futuro barão do Triunfo, comandante da guarda Nacional em Rio Pardo, informava o conselheiro Ângelo Muniz da Silva Ferraz, então presidente da Província, que, três dias antes, recebera correspondência do capitão comandante da $5^{\mathrm{a}}$ Companhia, do $22^{\circ}$ Corpo da Guarda Nacional de Rio Pardo, noticiando que soubera, no mesmo dia 28, de "uma sedição de escravos no Distrito do Capivari, Encruzilhada e Erval". Encabeçariam o movimento "vários desertores do Exército e criminosos evadidos da prisão", com o objetivo de "matarem várias pessoas e roubarem suas casas". José Joaquim de Andrade Neves ordenara que seu subordinado reunisse imediatamente sua tropa e prevenisse o subdelegado e o delegado de Polícia do termo. A seguir, partira, no "mesmo dia, em pessoa, à frente de alguns Guardas Nacionais e praças de Cavalaria de Linha", de Rio Pardo, para o distrito de Capivari, presunto local do "primeiro assalto". Ao chegar ao destino, na noite do mesmo dia 28, colocara guardas nacionais "em diversas pontes até as imediações da Encruzilhada", para impedir a fuga dos “criminosos". (OFICIO, 1859)

Prevenidos do deslocamento das tropas, os facinorosos fugiram, embrenhando-se nas matas do distrito de Santo Amaro. Entre os positivamente envolvidos estariam os quatro irmãos Botelhos, desertores - Manoel Joaquim, o "Menino Diabo", Lino dos Santos, Joaquim dos Santos e José dos Santos; Laurindo, o "Pescoço Grosso", criminoso fugido da cadeia; “um Valeriano"; “um 
fulano Meirelles", além de outros, de nomes desconhecidos. José Joaquim informava o presidente da Província que, desbaratado o intento, retornara a Rio Pardo, deixando alguma tropa às ordens do subdelegado de polícia. (Idem) Sobre os objetivos da conspiração, um "preto" que fora "agarrado" informava que os "malvados" haviam seduzido a "escravatura para conseguirem seus fins", propondo "dar o grito de liberdade aos escravos nos pontos em que atacassem" e saquear residências. Prometerem que os envolvidos na ação enriqueceriam "com os despojos das vítimas e tomariam por suas companheiras as filhas dos assassinados".

\subsection{Após o Grito da Liberdade}

Em síntese preparada para o ministro da Justiça, na Corte, afirmava-se que, segundo o "depoimento de um dos negros, os desertores, quando dessem o grito de liberdade, matariam os senhores dos pretos, tomando-lhes as filhas para suas amásias". José Joaquim finalizava sugerindo manter tropas entre os distritos de Capivari e Encruzilhada, para "restabelecer a tranquilidade pública". (Idem) O plano consistia em marchar até Encruzilhada do Sul, tomar o armamento da Polícia, "dar o grito de liberdade aos escravos". O crioulo Joaquim, de José de Souza Jardim, confidenciara a Cândido Furtado Fanfa, morador do Capivari, que Manoel Joaquim Botelho, líder do movimento, arrolava cativos para a revolta. Candido informara os proprietários da região e o capitão Antônio Pereira Franco, comandante da Companhia de Guardas Nacionais do Distrito do Capivari.

As tropas policias e militares dispersaram os conspiradores antes da eclosão do movimento, sendo presos e duramente castigados diversos cativos, entre eles, João, escravo de Bartolomeu Luiz Barreto, e Marcolino, de Fortunato Luís Barreto, do Capivari. Os desertores teriam fugido para o Uruguai. Segundo o relatório do Joaquim Fernandes Leão à Assembleia, de novembro 1859, "Feliciano [sic] Botelho" fora preso, em maio, "no termo de Taquari", pelo delegado de polícia, José de Azambuja Villa Nova.” No mesmo relatório de novembro de 1859, Joaquim Fernandes propunha: “Já estava por assim dizer esquecida a tentativa dos Botelhos, quando em Piratini correu o boato de que se tramava outra insurreição. Fiz seguir para ali uma força de polícia; as autoridades locais porém, com a atividade e zelo que desenvolveram, e as providencias que tomaram, fizeram desaparecer os receios, que se tinham manifestado. Alguns escravos comprometidos no plano de insurreição foram convenientemente corrigidos: toda as combinações se desfizeram e a confiança voltou ao animo dos habitantes de Piratini.”(RELATÓRI, 1859: 4.) 
O primeiro sucesso, apresentado como simples sedição e sedução de cativos promovida por desertores e criminosos, foi talvez - a exceção das fracassadas rebeliões de Alexandre Luís de Queirós e Vasconcelos, em 1803, 1830 e 1831, a única conspiração que conhecemos no Rio Grande de homens livres de promoverem a liberdade de trabalhadores escravizados, pelas armas, apoiados nos mesmos. O segundo movimento tem sua veracidade sugerida pelo castigo recebido pelos cativos. Os anos 1860 seriam terribilis para os escravistas sulinos, devido aos múltiplos, amplos e sérios complôs servis. (MAESTRI, 2011: 61-76.)

\section{BIBLIOGRAFIA}

AHRGS. (1798); Real Feitoria do Cânhamo (RFLC), Man. único, Minuta de nomeação 16.04.1801; RFLC, Inspetor A.J. M. Sarmento.

Arquivo Municipal de Porto Alegre. (AMPA). (1838); Livro de Atas da Câmara Municipal de Porto Alegre, 13 de outubro.

ASSUMPÇÃO, Jorge Euzébio. (2013); Pelotas: escravidão e charqueadas: 1780-1888. Porto Alegre: FCM Editora.

BAKOS, Margaret. [2007]; Abolicionismo no Rio Grande do Sul. Caderno de História, 29. Governo do Estado do Rio Grande do Sul, Secretaria de Estado da Cultura, Mônica Leal, Memorial do RGS, http://www.memorial.rs.gov.br/cadernos/abolicao1.pdf. Acessado em 01.05.2014.

BENTO, Cláudio Moreira. (1976); O negro e descendentes na sociedade do RS. (1863-1975). Porto Alegre: Grafosul; IEL.

CHAVES, José Antônio Gonçalves. (2004); Memórias Ecônomo-politicas sobre a administração pública do Brasil. 4 ed. São Leopoldo: EdiUnisinos.

CONRAD, Robert Edgar. (1985); Tumbeiros: o tráfico escravista para o BrasiL. São Paulo: Brasiliense.

CONRAD, R. E. (1978); Os últimos anos da escravatura no Brasil. 2 ed. Rio de Janeiro: Civilização Brasileira, Brasília: INL.

COSTA, Emília Viotti da. (1982); Da senzala à colônia. 2 ed. São Paulo: Ciências Humanas.

ELOY, Rosa Alonso; TOURON, Lucia Sala de; TORRE, Nelson de la; RODRIGUES, Julio Carlos. (1970); La oligarquía oriental en la Cisplatina. Montevideo: Pueblos Unidos.

FEE. (1981); Da província de São Pedro a Estado RS: censos do RGS. 1803-1950. Porto Alegre: 
MCSHJC.

FLORES, Hilda Agnes Hübner. (1995); Alemães na Guerra dos Farrapos, Porto Alegre: EDIPUCRS.

FLORES, Moacyr. (2004); Negros na revolução farroupilha: traição em Porongos e farsa em Ponche Verde. Porto Alegre: EST.

GUTIÉRREZ, Ester J. B. (2011); Negros, Charqueadas \& Olarias: um estudo sobre o espaço pelotence. 3 ed. Passo Fundo: UPF Editora. (Coleção Malungo, 20).

JOHANN, R.F. (2011); Na trama dos escravos de sua Majestade: o batismo e as redes de compadrio dos cativos da Real Feitoria de Linho Cânhamo. 1788-1798. Trabalho de Conclusão de Curso, IFCH-UFRGS. http://www.lume.ufrgs.br/bitstream/handle/10183/28999/000774636.pdf? sequence $=1$. Acessado 01.05.2014

LAYTANO, Dante. (1958); O negro no Rio Grande do Sul. Primeiro seminário de estudos gaúchos. 3.9-4.10 de 1957. PUCRS, Porto Alegre: Champagnat.

LESSA. Barbosa. (2000); Rio Grande do Sul: prazer em conhecê-lo: como surgiu o Rio Grande. 3. Porto Alegre: AGE.

LIMA, Solimar O. (2006) Triste pampa: resistência e punição de escravos em fontes judiciárias no RS. 1818-1833. 2 ed. Passo Fundo: UPF Editora. (Coleção Malungo, 10).

MAESTRI, Mário. (1984); O escravo no Rio Grande do Sul: a charqueada e a gênese do escravismo gaúcho. Porto Alegre: EST; Caxias, EdUCS.

MAESTRI, Mário. (1988); A cruz e a senzala: a Igreja no Brasil escravista.. D.O. Leitura, São Paulo, São Paulo, v. 6, 06 mar.

MAESTRI, Mário. (1996); "Pampa negro: quilombos no Rio Grande do Sul”. REIS, João José \& GOMES, Flávio dos Santos. Liberdade por um fio: história dos quilombos no Brasil. São Paulo: Companhia das Letras. pp. 291-331.

MAESTRI, Mário. (2001); “A escravidão e a gênese do Estado nacional brasileiro”. ANDRADE, Manuel Correia de et al. Além do apenas moderno. Brasília: CNPq; Recife, Fundação Joaquim Nabuco/Editora Massangano.

MAESTRI, Mário. (2002); Deus é grande, o mato é maior: trabalho e resistência escrava no Rio Grande do SuL. Passo Fundo: UPF. (Malungo, 5).

MAESTRI, Mário. (2010) "O cativo, o gaúcho e o peão: considerações sobre a fazenda pastoril riograndense (1680-1964)". MAESTRI, Mário \& LIMA, Solimar O. (Org.) Peões, vaqueiros \& 
cativos campeiros: estudos sobre a economia pastoril no Brasil. Passo Fundo: UPF Editora [CNPQ]. T. 2. Pp. 212-300.

MAESTRI, Mário. (2011); Pampa Negro: Agitações, Insubordinações e Conspirações Servis no Rio Grande do Sul, 1863-1868. Sæculum, PPGH Universidade Federal da Paraíba, nº 25, jul./dez.. http://periodicos.ufpb.br/ojs/index.php/srh/article/viewFile/14007/7929

MENZ, Maximiliano M. (2005); “Os escravos da Feitoria do Linho Cânhamo: trabalho, conflito e negociação". Afro-Ásia, Salvador, 32. www.afroasia.ufba.br/pdf/ afroasia32_139_158_Feitoria Linho. PDF. Acessado em 01/05/2014.

MORAES, Carlos de Souza. (1994); Feitoria do Linho Cânhamo. Porto Alegre: Parlenda, 1994.

Oficio de José Joaquim de Andrade Neves. (1859), Comandante Superior da Guarda Nacional de Rio Pardo, 31.3. ao Ilmo. Exmo. Sr. Conselheiro Ângelo Muniz da Silva Ferraz, Presidente da província. AN, RJ, série IJ (1) 582

PALERMO, Eduardo Ramón. (2013). Tierra esclavizada: el norte uruguayo en la primera mitad del siglo 19. Montevideo: Tierra Adentro.

PETIZ, Silmei. (2006); Buscando a liberdade: as fugas de escravos da província de São Pedro para o além-fronteira (1815-1851). Passo Fundo: EdiUPF.

PETRY, Leopoldo. (1977); “O município de São Leopoldo”. Anais do I Congresso de História e Geografia de São Leopoldo. Porto Alegre: Globo, 1947. Apud: CARDOSO, Fernando Henrique. Capitalismo e escravidão no Brasil Meridional: o negro na sociedade escravocrata do Rio Grande do Sul. 2 ed. Rio de Janeiro: Paz \& Terra.

PICCOLO, H. (Org.) (1992); A resistência escrava no Rio grande do Sul. Porto Alegre: UFRGS, Curso de pós-graduação em história.

PICCOLO, H. (1993); Da descolonização à consolidação da República: a questão do separatismo versus federação no Rio Grande do Sul, no século XIX. Indicadores Econômicos FEE, v.21, n.3, http://revistas.fee.tche.br/index.php/indicadores/article/viewFile/597/837. Acessado em 01.05.2010.

Relatório. (1848). Do vice-presidente da província de São Pedro do Rio Grande do Sul, João Capistrano de Miranda Castro, na abertura da Assembléa Legislativa Provincial em 4 de março de 1848, acompanhado do orçamento para o anno financeiro de 1848-1849. Porto Alegre, Typ. do Porto Alegrense.

Relatório. (1854). Do presidente da Província de São Pedro do Rio Grande do Sul, João Lins Vieira 
Cansansão de Sinimbu, na abertura da Assembléia Legislativa Provincial, em 2 de outubro.

Relatório. (1859) Apresentado a Assembleia Provincial de S. Pedro do Rio Grande do Sul na 2.a sessão da 8.a legislatura pelo conselheiro Joaquim Antão Fernandes Leão. Porto Alegre, Typ. do Correio do Sul.

RIBEIRO, José Iran. (2005); Quando o Serviço os chama: Milicianos e Guardas Nacionais no Rio Grande do Sul. (1825-1845). Santa Maria: EdiUFSM, 2005;

ROCHE, Jean. (1969). A colonização alemã e o Rio Grande do Sul. I: Porto Alegre: Globo. Vol. 1.

SANTOS, Corcino Medeiros dos. (1984). Economia e sociedade do Rio Grande do Sul: século XVII. São Paulo: CEN; INL, Fundação Pró-Memória.

SIMÃO, Ana. (2002) Resistência e acomodação servil em Pelotas. Passo Fundo: EdiUPF. (Malungo, 9.)

SPALDING, Walter. (1967); Pequena história de Porto Alegre. Porto Alegre: Sulina.

SPALDING, Walter. (1969) Construtores do Rio Grande. Porto Alegre: Sulina. Vol. 1.

TRAMONTINI, Marcos Justo. (2000); A organização social dos imigrantes: a colônia de São Leopoldo na fase pioneira (1824-1850). São Leopoldo: Unisinos.

WEIMER, Günter. (1991); O trabalho escravo no Rio Grande do Sul. Porto Alegre, UFRGS/SAGRA.

WIEDERSPAHN, Henrique Oscar. (1984); O General Farroupilha João Manuel de Lima e Silva. Porto Alegre: EST, Sulina; Caxias do Sul: UCS. 